\title{
Effect of humidity on fatigue strength of shot peened maraging steel
}

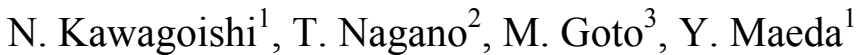 \\ \& M. Moriyama ${ }^{4}$ \\ ${ }^{1}$ Department of Mechanical Engineering, Kagoshima University, Japan \\ ${ }^{2}$ Miyakonojo National College of Technology, Japan \\ ${ }^{3}$ OitaUniversity, Japan \\ ${ }^{4}$ Dai-ichi University College of Technology, Japan
}

\begin{abstract}
Rotating bending fatigue tests were carried out for maraging steels using shot peened and electro-polished specimens with various hardness of HV550 HV750 in atmosphere and controlled humidity to investigate the effects of hardness and humidity on the fatigue strength. Fracture occurred from specimen surface in short life region and from inclusion of specimen subsurface in long life one in shot peened specimen, while only surface fracture occurred in electro-polished specimen in wide life range. Hardness dependence of fatigue strength was different between surface fracture and internal one. That is, fatigue strength for internal fracture increased with increase in hardness within the tested hardness, while there was the peak of fatigue strength around HV600 and then fatigue strength decreased with increase in hardness in the relation between hardness and fatigue strength for surface fracture. These results were discussed from the sensitivities of fatigue strength for notch and humidity.
\end{abstract}

Keywords: fatigue, maraging steel, shot-peening, hardness dependence, humidity, fracture mechanism.

\section{Introduction}

Maraging steel has the highest static strength among steels for practical use. However, the fatigue strength is very low in comparison with its high static strength [1]. Therefore many studies on fatigue mechanism of the steel have been conducted to improve the fatigue strength. Authors reported that surface treatments like a nitriding and shot peening and formation of reverted austenite 
were effective to improve the fatigue strength of the steel [2-4]. On the other hand, fatigue strength of high strength steels are sensitive not only for notch but also for humidity $[5,6]$. The sensitivities of fatigue strength for notch and humidity increase with increasing hardness.

In the present study, rotating bending fatigue tests were carried out for maraging steels using shot peened and electro-polished specimens with various hardness of HV550 HV695 in atmosphere and controlled humidity to investigate the hardness dependence of fatigue strength and the effect of humidity on the fatigue strength.

\section{Material and experimental procedures}

The materials used were two kinds of $18 \%$ Ni maraging steels (300 grade and 350 grade) whose chemical compositions in mass \% were shown in table 1 . The materials were solution treated for $5.4 \mathrm{ks}$ at $1123 \mathrm{~K}$ in vacuum, followed by air cooling and age hardened at different conditions shown in table 2 in a salt bath to change the hardness. The mechanical properties of aged specimen were also shown in table 2 .

Table 1: Chemical composition.

\begin{tabular}{|c|c|c|c|c|c|c|c|c|c|c|c|}
\hline Grade & \multicolumn{10}{|c|}{ Composition, mass\% } \\
\cline { 2 - 12 } & $\mathrm{C}$ & $\mathrm{Si}$ & $\mathrm{Mn}$ & $\mathrm{P}$ & $\mathrm{S}$ & $\mathrm{Ni}$ & $\mathrm{Mo}$ & $\mathrm{Co}$ & $\mathrm{Ti}$ & $\mathrm{Al}$ & $\mathrm{Fe}$ \\
\hline 300 & 0.01 & 0.05 & 0.03 & 0.002 & 0.002 & 18.7 & 5.0 & 8.94 & 0.92 & 0.12 & $\mathrm{Bal}$ \\
\hline 350 & 0.001 & 0.01 & 0.01 & 0.001 & 0.001 & 17.89 & 4.27 & 12.36 & 1.30 & 0.08 & $\mathrm{Bal}$ \\
\hline
\end{tabular}

Table 2: $\quad$ Aging conditions and mechanical properties.

\begin{tabular}{|c|l|c|c|c|c|}
\hline \multicolumn{2}{|c|}{} & $\begin{array}{c}\text { Hardness } \\
H V\end{array}$ & $\begin{array}{c}0.2 \% \text { proof } \\
\text { stress } \\
\sigma_{0.2}(\mathrm{MPa})\end{array}$ & $\begin{array}{c}\text { Tensile } \\
\text { strength } \\
\sigma_{B}(\mathrm{MPa})\end{array}$ & $\begin{array}{c}\text { Elongation } \\
\delta(\%)\end{array}$ \\
\hline \multirow{5}{*}{300 grade } & 550 & 1730 & 1833 & 11.3 \\
\cline { 2 - 6 } & $753 \mathrm{~K}-2.8 \mathrm{ks}$ & 570 & 1835 & 1890 & 7.3 \\
\cline { 2 - 6 } & $753 \mathrm{~K}-6 \mathrm{ks}-11 \mathrm{ks}$ & 604 & 1730 & 1833 & 11.3 \\
\cline { 2 - 6 } & $753 \mathrm{~K}-48 \mathrm{ks}$ & 634 & 2073 & 2156 & 8.5 \\
\cline { 2 - 6 } & $743 \mathrm{~K}-320 \mathrm{ks}$ & 670 & 2201 & 2257 & - \\
\hline 350 grade & $753 \mathrm{~K}-150 \mathrm{ks}$ & 695 & 2272 & 2310 & - \\
\cline { 2 - 7 } & $753 \mathrm{~K}-150 \mathrm{ks}+673 \mathrm{~K}-3.6 \mathrm{ks}$ & 750 & - & - & - \\
\hline
\end{tabular}

Figure 1 shows shape and dimensions of specimen. After machining the specimens, the parts of the specimens were electro-polished by about $20 \mu \mathrm{m}$ from the surface layer and the rest were shot peened under the conditions shown in table 3. Distributions of hardness and residual stress were measured by using a micro Vickers hardness tester $(1.97 \mathrm{~N})$ and an $\mathrm{X}$ ray diffraction device $(\mathrm{Cr}-\mathrm{K} \alpha)$, respectively. Fatigue tests were carried out using a rotating bending fatigue 
testing machine with a capacity of $15 \mathrm{Nm}$ operating at about $50 \mathrm{~Hz}$ in ambient atmosphere, where relative humidity $(\mathrm{RH})$ was about $60-80 \%$ and controlled humidity of $25 \%$ and $85 \%$. The humidity was controlled by setting the testing machine in a cabin and using a humidifier or a dehumidifier.

Table 3: $\quad$ Shot peening conditions.

\begin{tabular}{|c|c|c|c|c|c|c|c|}
\hline \multicolumn{4}{|c|}{ Blasting equipment } & \multicolumn{4}{|c|}{ Air type } \\
\hline \multirow{3}{*}{ Shot } & Material & \multicolumn{3}{|c|}{ Size $(\mathrm{mm})$} & \multicolumn{2}{|c|}{ Hardness } & $\begin{array}{l}\text { Specific } \\
\text { gravity }\end{array}$ \\
\hline & Steel & \multicolumn{3}{|c|}{$\Phi 0.3, \Phi 0.6, \Phi 1.1$} & \multicolumn{2}{|c|}{$H V=700$} & 7.5 \\
\hline & $\begin{array}{l}\text { Cemented } \\
\text { carbide }\end{array}$ & \multicolumn{3}{|c|}{$\Phi 0.05$} & \multicolumn{2}{|c|}{$H V=1400$} & 14 \\
\hline \multirow[t]{7}{*}{ Blastin } & & & \multicolumn{4}{|c|}{ Single shot } & Double shot \\
\hline & \multicolumn{2}{|c|}{ Shot size $(\mathrm{mm})$} & $\Phi 0.05$ & $\Phi 0.3$ & $\Phi 0.6$ & $\Phi 1.1$ & $\begin{array}{l}\Phi 1.1 \\
\Phi 0.05\end{array}$ \\
\hline & \multicolumn{2}{|c|}{$\begin{array}{l}\text { Arc hight } \\
(\mathrm{mm} \mathrm{A})\end{array}$} & 0.075 & 0.230 & 0.430 & 0.730 & $\begin{array}{l}0.730 \\
0.075\end{array}$ \\
\hline & \multicolumn{2}{|c|}{ Time $(\mathrm{sec})$} & 6 & 6 & 6 & 6 & $\begin{array}{r}12 \\
6\end{array}$ \\
\hline & \multicolumn{2}{|c|}{ Pressure ( $\mathrm{MPa}$ ) } & 0.3 & 0.3 & 0.3 & 0.3 & $\begin{array}{l}0.3 \\
0.3\end{array}$ \\
\hline & \multicolumn{2}{|c|}{ Distance $(\mathrm{mm})$} & \multicolumn{5}{|c|}{180} \\
\hline & \multicolumn{2}{|c|}{ Coverage (\%) } & \multicolumn{5}{|c|}{300} \\
\hline
\end{tabular}

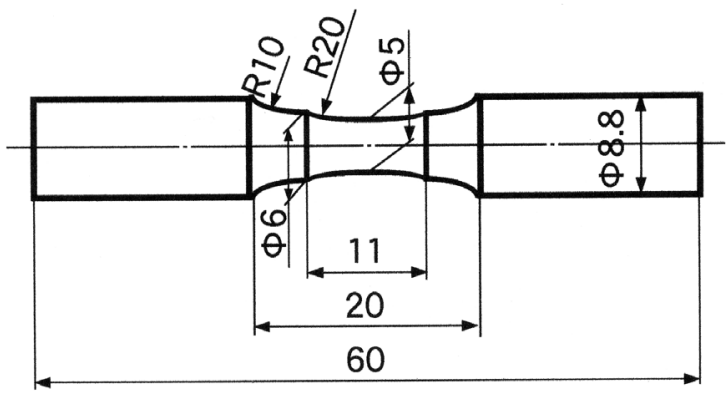

Figure 1: $\quad$ Shape and dimensions of specimen.

\section{Results and discussion}

Figure 2 shows distributions of hardness and residual stress in shot-peened specimens. Marked hardening was generated in all materials. The harder material is, the larger the surface hardness is. And the hardened depth is smaller in harder 
material. On the other hand, although compressive residual stress was generated by shot peening in all of the shot peened specimens, the maximum values and depths of stressed layer of these materials are nearly the same.

Figure 3 shows surface roughness of shot peened specimen. The surface roughness was decreased with increase in hardness of material.

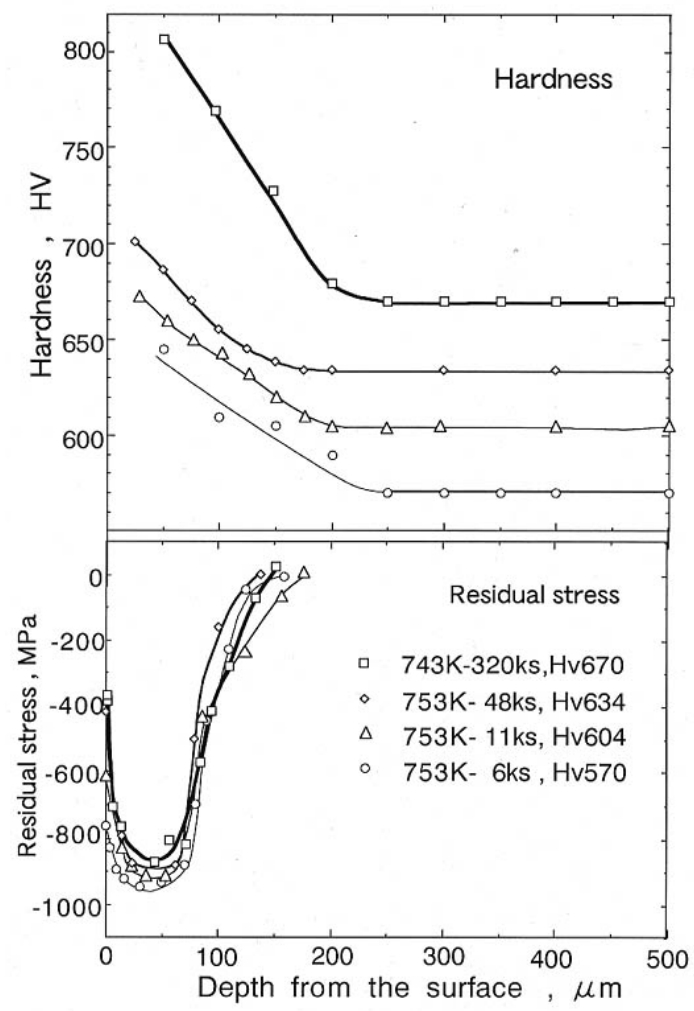

Figure 2: Distributions of hardness and residual stress.

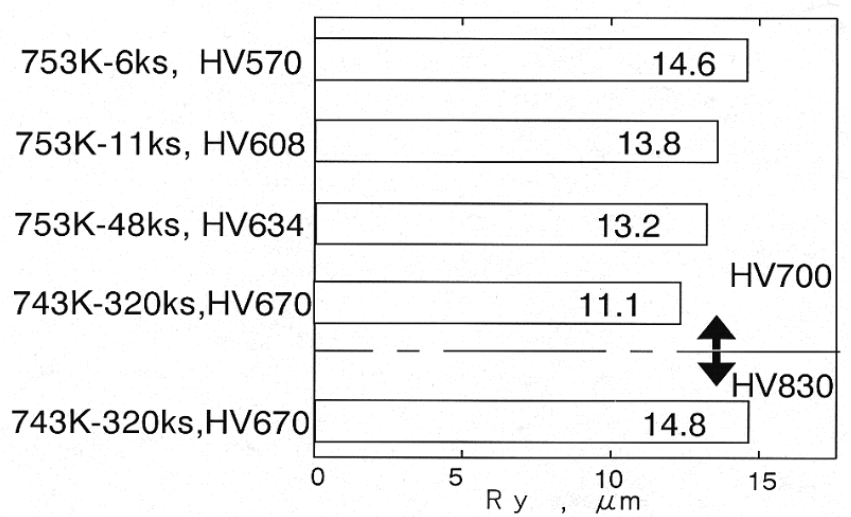

Figure 3: $\quad$ Surface roughness of shot peened specimen. 


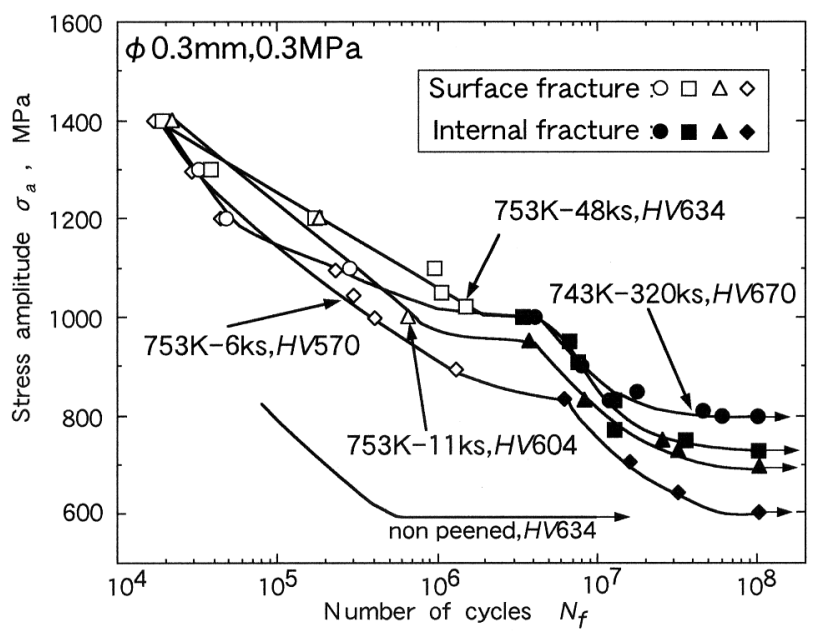

Figure 4: $S$ - $N$ curves of shot peened specimen.

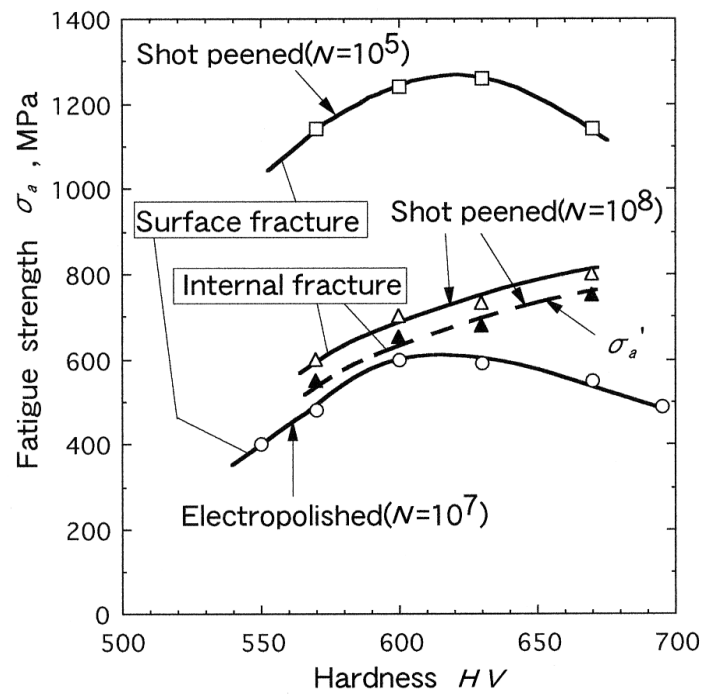

Figure 5: Relation between fatigue strength and hardness.

Figure 4 shows $S-N$ curves of shot-peened specimens. In the figures, open marks and solid ones mean a surface fracture and an internal one, respectively. In all of shot-peened specimens, fracture initiated from the specimen surface in the short life region and an internal fracture occurred from the subsurface in the long life region, while only surface fracture occurred from specimen surface in electro-polished specimens in wide life range. Fatigue strength was increased markedly by shot peening, while the increase in fatigue strength was small in long life region. $S-N$ curves of shot peened specimens show duplex $S-N$ shape 
similar to the ones of many high strength steels and surface treated steels [7-9]. However, the horizontal line in $S$ - $N$ curve, which corresponds to the fatigue limit for surface fracture, is not clear.

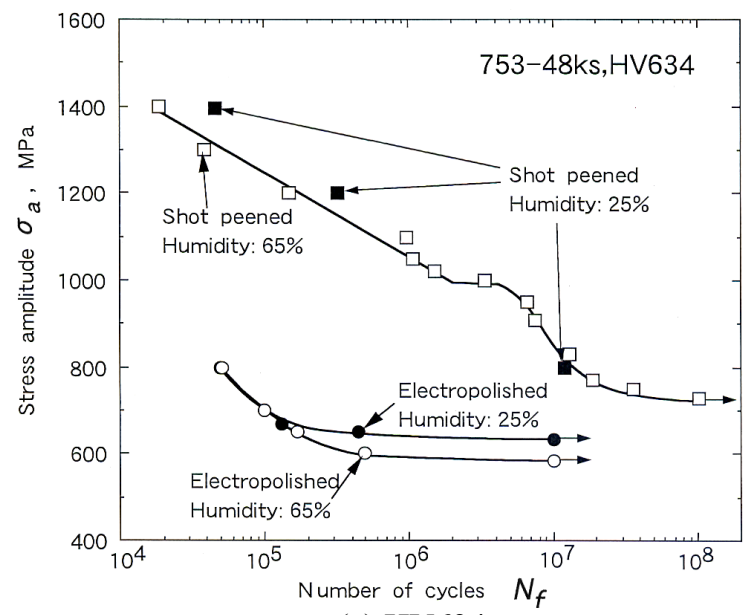

(a) HV634

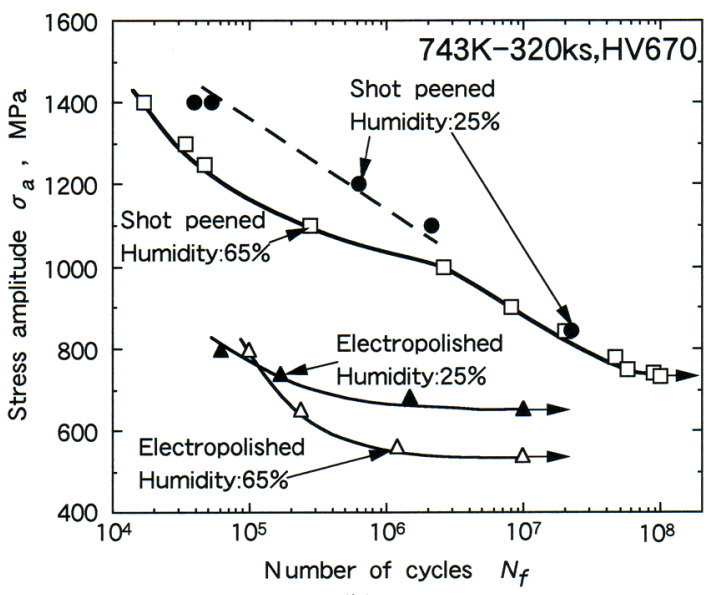

(b) HV670

Figure 6: $\quad S-N$ curves of shot peened specimen in humidity of $25 \%$.

Figure 5 shows hardness dependence of fatigue strength of shot-peened specimens. In the figure, fatigue strengths at $10^{5}$ and $10^{8}$ are indicated as ones for surface fracture and internal one, respectively. Although fatigue strength for internal fracture increases with increasing hardness, one for surface fracture shows peak value around HV600 and then decreases with increasing hardness. In general, linier relation between fatigue strength and hardness holds until around HV400 and beyond the hardness, fatigue strength decreases in high strength steels $[10,11]$. The reason for this breakdown in the relation was explained by 
the high notch sensitivity of high strength steel $[5,6]$. From this standpoint, the effect of hardness on fatigue strength should be the same regardless of fracture type. Moreover, surface roughness decreased with increase in hardness in this study as shown in fig.3. Therefore, it is difficult to explain the difference in hardness dependence between fatigue strengths for surface fracture and internal one from viewpoint of notch sensitivity. On the other hand, fatigue strength of high strength steel is affected by environment even in an ambient air. Therefore, in the following, the results mentioned above will be investigated from viewpoint of effect of humidity.

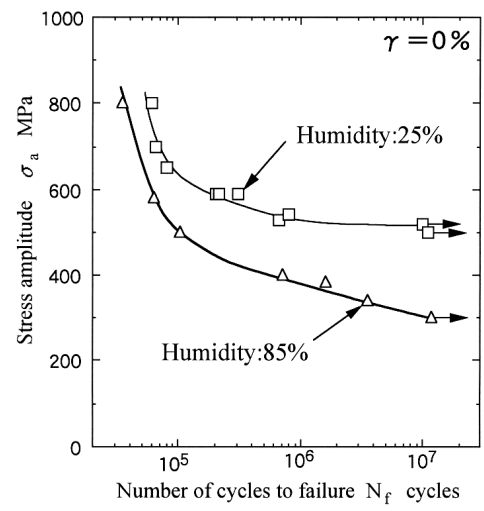

(a) HV550

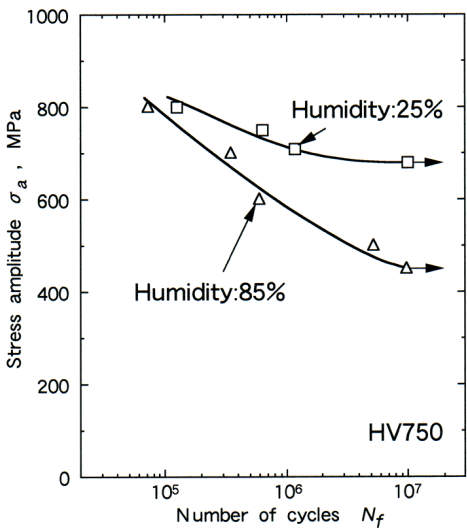

(b) HV750

Figure 7: $\quad S-N$ curves of electro-polished specimen in humidity of $25 \%$ and $85 \%$.

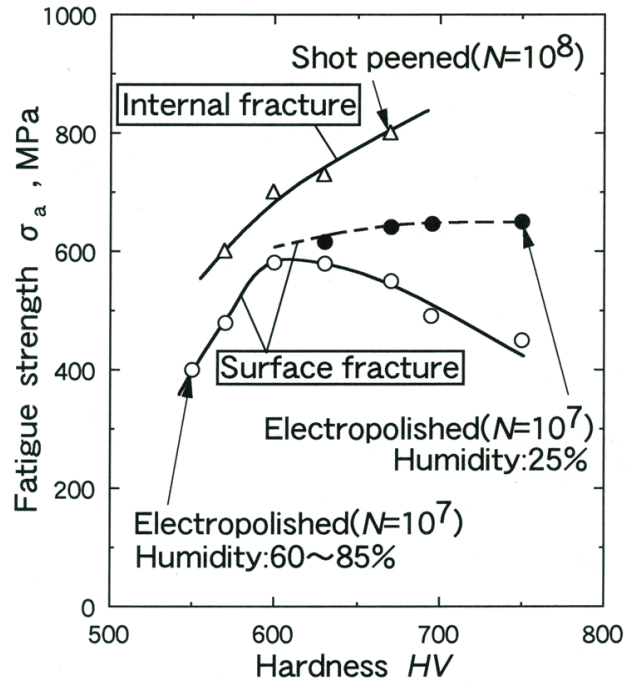

Figure 8: Relation between fatigue strength and hardness. 
Figure 6 is $S-N$ curves of shot-peened specimens showing the effect of humidity in cases of materials of HV634 and 695. Fatigue strength in humidity of $25 \%$ increases in the surface fracture region in comparison with the results in ambient air, though fatigue strength for internal fracture does not change.

Figure 7 shows $S$ - $N$ curves of electro-polished specimens in humidity of $25 \%$ and $85 \%$. In electro-polished specimens, all of fractures occurred from specimen surface. Large decrease in fatigue strength for surface fracture is confirmed in high humidity.

Figure 8 shows relation between fatigue strength of shot peened specimen and hardness in low humidity in addition to the results in fig. 5. Linear relation between fatigue strength and hardness holds beyond HV600 even in fatigue strength for surface fracture. That is, hardness dependence of fatigue strength for surface fracture is nearly the same as the one for internal fracture.

Figure 9 shows fracture surfaces in case of the specimen of HV670. Intergranular cracks are observed on fracture surface as indicated arrow mark in high humidity, while there is no intergranular crack in low humidity. That is, a main reason for lower fatigue strength in high humidity is an acceleration of crack growth by intergranular crack.

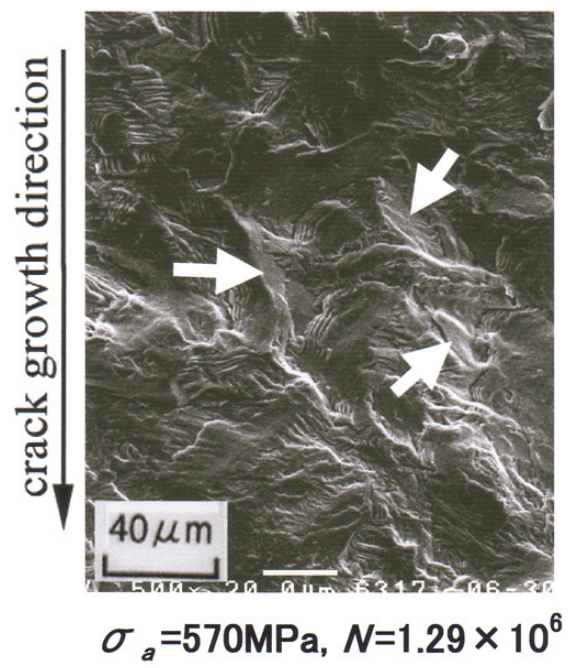

(a) In high humidity

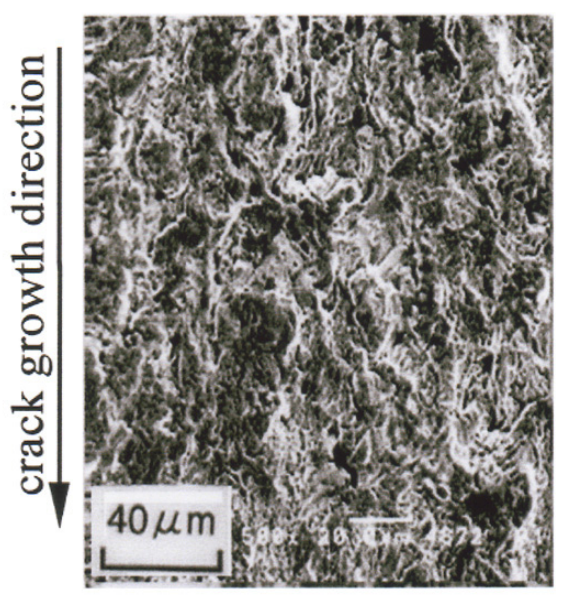

$\sigma_{a}=700 \mathrm{MPa}, N=1.62 \times 10^{6}$

(b) In low humidity

Figure 9: $\quad$ Fracture surfaces of electro-polished specimen (HV670).

From mentioned above, in considering the hardness dependence of fatigue strength in high strength steel, we must notice not only about notch sensitivity but also about humidity-sensitive. Especially an attention to the effect of humidity on fatigue strength of maraging steel should be paid, because the range of humidity from $25 \%$ to $85 \%$ is not special case as ambient air in practical use. 


\section{Conclusions}

Hardness dependence of fatigue strengths for surface fracture and internal one of maraging steel was investigated using shot peened specimens under rotating bending. Fatigue strength for surface fracture was evaluated by the fatigue strength at $10^{5}$ cycles and that for internal fracture was by the one at $10^{8}$ cycles. Both of fatigue strengths for surface fracture and internal one increased with increase in hardness. However, the proportional relationship between fatigue strength and hardness existed till higher hardness in the fatigue strength for internal fracture than in the one for surface fracture. The difference in the hardness dependence of fatigue strength was explained from the influence of humidity.

\section{References}

[1] Zackey, V. F., Parker, E. R. \& Wood, W. E. Proc. of the $3^{\text {rd }}$ Inter. Conference on the Strength of Metals and Alloys, 25, pp. 175-179, 1973.

[2] Fukada, K., Kawagoishi, N., Morino, K. \& Nisitani, H., Steel, Surface Treatment V, pp.203-208, 2001.

[3] Kawagoishi, N., Nagano, T., Moriyama, M. \& Kondo, E., Key Engineering, Vols 348-349, pp.537-540, 2007.

[4] Kawagoishi, N. Nagano, T., Moriyama, M. Ohzono, Y. \& Kondo, E., Jour. of Soc. of Mater. Sci., Japan, Vol. 55, pp.843-848, 2006.

[5] Murakami, Y. \& Shimizu, M., Trans. Jpn. Soc. Mech. Eng. A. Vol.54, pp.413-425, 1983.

[6] Endo, K,. Komai, K. Fujimoto, T. \& Matsuda, Y., Trans. Jpn. Soc. Mech. Eng. A., Vol.45, pp.1152-1159, 1979.

[7] Kawagoishi, N., Morino, K. Fukada, K, Chen, Q. \&Kondo, E., Steel, Surface Treatment V,pp.209-217, 2001.

[8] Shiozawa, K. Tao, L. \& Ishihara, S., Jour. of Soc. of Mater. Sci., Japan, Vol. 48, pp.1095-1100, 1999.

[9] Nakajima, M., Sakai, T. \& Shimazu, T., Trans. Jpn. Soc. Mech. Eng. A., Vol.65, pp. 2504-2510, 1999.

[10] Masuda, C. Nishijima, S. \& Tanaka, Y., Trans. Jpn. Soc. Mech. Eng. A. Vol.52, pp.847-852, 1986.

[11] Sawai, T., Kimura, Y., Tusaki, K., Takeuchi, E. \& Matsuoka, S., Trans. Jpn. Soc. Mech. Eng. A., Vol.68, pp49-56, 2002. 